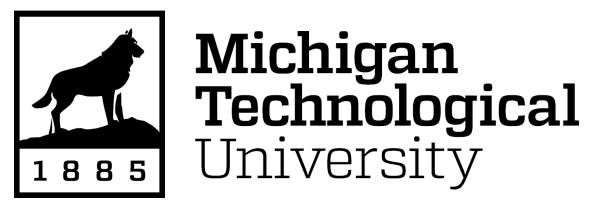

Michigan Technological University Digital Commons @ Michigan Tech

8-7-2007

\title{
Strain-induced formation of carbon and boron clusters in boron carbide during dynamic indentation
}

\author{
Dipankar Ghosh \\ University of Florida \\ Ghatu Subhash \\ University of Florida \\ Chee Huei Lee \\ Michigan Technological University \\ Yoke Khin Yap \\ Michigan Technological University
}

Follow this and additional works at: https://digitalcommons.mtu.edu/physics-fp

Part of the Physics Commons

\section{Recommended Citation}

Ghosh, D., Subhash, G., Lee, C. H., \& Yap, Y. K. (2007). Strain-induced formation of carbon and boron clusters in boron carbide during dynamic indentation. Applied Physics Letters, 91(6), 061910-1-061910-3. http://dx.doi.org/10.1063/1.2768316

Retrieved from: https://digitalcommons.mtu.edu/physics-fp/303

Follow this and additional works at: https://digitalcommons.mtu.edu/physics-fp

Part of the Physics Commons 


\section{Strain-induced formation of carbon and boron clusters in boron carbide during dynamic indentation}

Cite as: Appl. Phys. Lett. 91, 061910 (2007); https://doi.org/10.1063/1.2768316

Submitted: 07 May 2007 . Accepted: 12 July 2007. Published Online: 07 August 2007

Dipankar Ghosh, Ghatu Subhash, Chee Huei Lee, and Yoke Khin Yap

ARTICLES YOU MAY BE INTERESTED IN

Raman spectroscopy of pressure-induced amorphous boron carbide

Applied Physics Letters 88, 131905 (2006); https://doi.org/10.1063/1.2189826

Influence of stress state and strain rate on structural amorphization in boron carbide Journal of Applied Physics 111, 063523 (2012); https://doi.org/10.1063/1.3696971

Nanoindentation and Raman spectroscopy studies of boron carbide single crystals

Applied Physics Letters 81, 3783 (2002); https://doi.org/10.1063/1.1521580

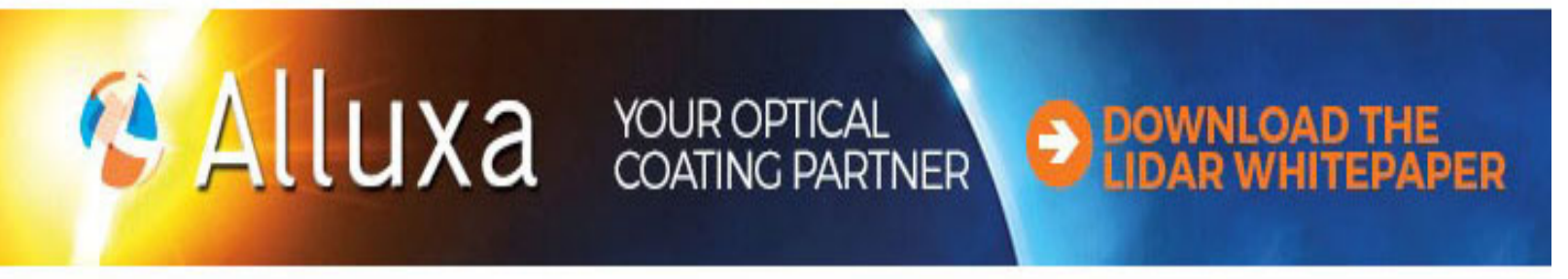




\title{
Strain-induced formation of carbon and boron clusters in boron carbide during dynamic indentation
}

\author{
Dipankar Ghosh and Ghatu Subhash ${ }^{\text {a) }}$ \\ Department of Mechanical and Aerospace Engineering, University of Florida, Gainesville, \\ Florida 32611-6250 \\ Chee Huei Lee and Yoke Khin Yap \\ Department of Physics, Michigan Technological University, 1400 Townsend Drive, Houghton, \\ Michigan 49931-1295
}

(Received 7 May 2007; accepted 12 July 2007; published online 7 August 2007)

\begin{abstract}
The authors found that the level of amorphization or structural disorder in boron carbide is higher when induced by dynamic indentation compared to static indentation. Visible and uv Raman spectroscopies indicate that $s p^{2}$-bonded aromatic carbon clusters were formed, consistent with the detected photoluminescence spectra. Infrared absorption shows that amorphous boron clusters were created by dynamic indentation which has strain rates $\sim 10^{8}$ order higher than that introduced by static indentation. The decreased intensity of infrared stretching mode of carbon-boron-carbon $(\mathrm{CBC})$ chains also suggests that amorphization is due to the collapse of $\mathrm{B}_{11} \mathrm{C}(\mathrm{CBC})$ unit cells, which reorganize into the energetically favorite carbon and boron clusters. (C) 2007 American Institute of Physics. [DOI: 10.1063/1.2768316]
\end{abstract}

Polycrystalline boron carbide $\left(\mathrm{B}_{4} \mathrm{C}\right)$ exhibits localized amorphization due to local collapse of crystal structure under high contact pressure experiments. ${ }^{1-4}$ Raman spectroscopic and temperature coefficient measurements of Raman bands on the nanoindented regions of single crystal $\mathrm{B}_{4} \mathrm{C}$ suggested the presence of aromatic rings, containing $s p^{2}$ hybridized carbon $(\mathrm{C})$ within amorphous $\mathrm{B}_{4} \mathrm{C}\left(a-\mathrm{B}_{4} \mathrm{C}\right)$ along with boron (B) atoms present either as $\mathrm{B}$ clusters or within aromatic rings. ${ }^{4}$ Fanchini et al. ${ }^{5}$ stated that amorphization in $\mathrm{B}_{4} \mathrm{C}$ may trigger from the collapse of $\mathrm{B}_{12}(\mathrm{CCC})$ polytype instead of $\mathrm{B}_{11} \mathrm{C}(\mathrm{CBC})$, and $a-\mathrm{B}_{4} \mathrm{C}$ may contain some segregated mixture of amorphous carbon $(a-\mathrm{C})$ and boron icosahedrons $\left(\mathrm{B}_{12}\right)$. But any experimental evidence of $a-\mathrm{C}$ and $\mathrm{B}_{12}$ within $a-\mathrm{B}_{4} \mathrm{C}$ is still lacking. Also, $\mathrm{B}_{4} \mathrm{C}$ is generally accepted to have $\mathrm{B}_{11} \mathrm{C}(\mathrm{CBC})$ polytype instead of $\mathrm{B}_{12}(\mathrm{CCC}){ }^{6,7}$ Therefore, the exact mechanism of $\mathrm{B}$ and $\mathrm{C}$ cluster formation within $a-\mathrm{B}_{4} \mathrm{C}$ is unclear. Based on a series of microspectroscopic studies, including Raman (both uv and visible), photoluminescence (PL), and Fourier transformed infrared (FTIR) spectroscopy on the indented regions, we provide evidence for the formation of $a-\mathrm{C}$ and $a$-B clusters in $\mathrm{B}_{4} \mathrm{C}$.

It was earlier shown ${ }^{2}$ through visible Raman spectroscopy that $a-\mathrm{B}_{4} \mathrm{C}$ exists within the damaged regions beneath static and dynamic indentations of a polycrystalline $\mathrm{B}_{4} \mathrm{C}$. For static indentation, indentation load is transferred within $15 \mathrm{~s}$ (at a strain rate of $10^{-5} / \mathrm{s}$ ) whereas in dynamic indentation ${ }^{8}$ load is delivered within 100-200 $\mu$ s (at a strain rate of $10^{3} / \mathrm{s}$ ). These damaged regions were probed using (i) visible Raman (He-Ne laser, $632.8 \mathrm{~nm}, 1.96 \mathrm{eV}$ ), (ii) uv Raman (He-Cd laser, $325 \mathrm{~nm}, 3.80 \mathrm{eV}$ ), (iii) photoluminescence (He-Cd laser, $325 \mathrm{~nm}, 3.80 \mathrm{eV}$ ), and (iv) FTIR spectroscopy in a reflection mode under a microscope with a focusing diameter of $\sim 10 \mu \mathrm{m}$, close to the diffraction limit of infrared wavelengths.

\footnotetext{
${ }^{\text {a) }}$ Author to whom correspondence should be addressed; electronic mail:
} subhash@ufl.edu
Figures 1(a) and 1(b) show the visible Raman spectra collected from the unindented polished surface and damaged regions of static and dynamic indentations. For the unindented area, see Figs. 1(a) and 1(b), characteristic Raman peaks of $\mathrm{B}_{4} \mathrm{C}$ structure $e^{4,6,7}$ are detected within $200-1200 \mathrm{~cm}^{-1}$. A weak graphite $(G)$ peak, around $1575 \mathrm{~cm}^{-1}$, is attributed to the presence of small amount of free $\mathrm{C}$ associated with the unindented polycrystalline $\mathrm{B}_{4} \mathrm{C}$. Static indented regions exhibited similar spectra with a distinct disorder-induced $(D)$ peak $\left(\sim 1335 \mathrm{~cm}^{-1}\right)$ [see Figs. 1(a) and 1(b)]. The $G$ and $D$ peaks represent zone center phonons of $E_{2 g}$ symmetry and $K$-point phonons of $A_{1 g}$ symmetry of graphitic C, respectively. ${ }^{9,10}$ The $G$ peak is associated with in-plane bond-stretching motion of pairs of $s p^{2}$-bonded $\mathrm{C}$ atoms present either in olefinic chains or in aromatic rings whereas the $D$ peak corresponds to the breathing mode of aromatic rings.

Significant changes were detected for dynamically indented regions [see Fig. 1(a)]. Intense $G$ and $D$ peaks were detected around 1590 and $1335 \mathrm{~cm}^{-1}$, respectively. The evolution of these peaks for both type of indentations clearly suggest the formation of $s p^{2}$ hybridized aromatic $\mathrm{C}$ rings, indicating localized amorphization in $\mathrm{B}_{4} \mathrm{C} .{ }^{2-4}$ Also, the stronger $G$ and $D$ peaks induced by dynamic indentation suggests a higher level of structural damage or amorphization in $\mathrm{B}_{4} \mathrm{C}$, as compared to static indentation. ${ }^{2}$ This interpretation is also associated with the lower Raman shift of the characteristic breathing modes of the icosahedral $\mathrm{B}_{11} \mathrm{C}$ structures ${ }^{4,6,7}$ of crystalline $\mathrm{B}_{4} \mathrm{C}$ at $\sim 1082 \mathrm{~cm}^{-1}$ (for dynamic indentation) and at $\sim 1089 \mathrm{~cm}^{-1}$ (for static indentation) due to the strain induced by the amorphization.

Similar features were observed in uv Raman spectra, see Fig. 1(c), except that the two low frequency peaks of visible Raman spectra in the range from 250 to $350 \mathrm{~cm}^{-1}$ were absent. The origin of these two peaks is not well understood although they often appear in $\mathrm{B}_{4} \mathrm{C}$ ceramics. ${ }^{6}$ In addition, the ratio of intensities of $D$ peak to that of $G$ peak, i.e., $I_{D} / I_{G}$ is $\sim 0.6$ for uv Raman and is $\sim 1.1$ for visible Raman. The 


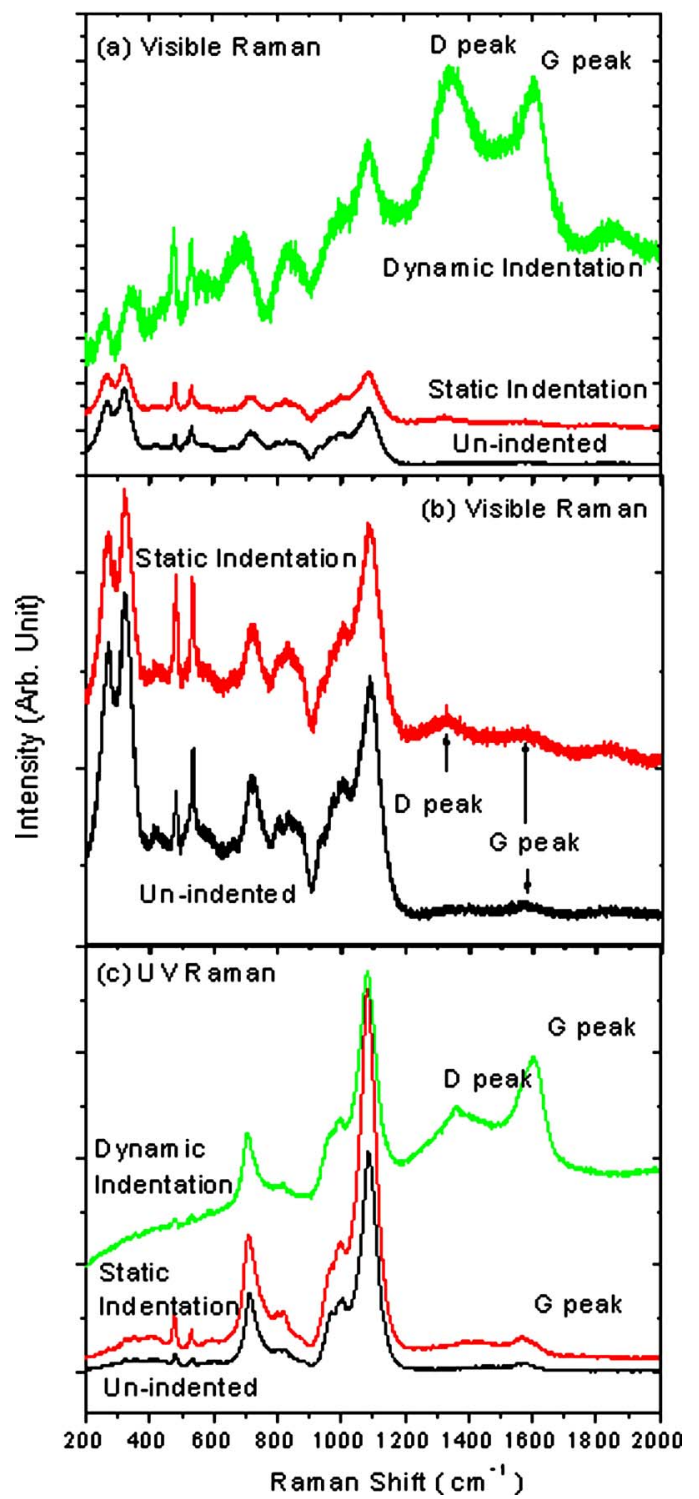

FIG. 1. (Color online) (a) Visible Raman spectra and (c) uv Raman spectra from the unindented surface and damaged regions beneath the static and dynamic indentations. (b) Magnified view of two of the spectra in (a).

observed $I_{D} / I_{G}$ values and their deviation (i.e., dispersion) are similar to that detected from hydrogenated and nonhydrogenated $a-\mathrm{C}$ films with $s p^{2}$-bonded C clusters. ${ }^{11,12}$ Also, $D$ peak disappears under uv excitation for disordered and nanocrystalline graphite but not for $a-\mathrm{C} .^{12}$ Besides, diamondlike carbon films with predominated $s p^{3}$-bonded $\mathrm{C}$ usually have low $I_{D} / I_{G}$ values $(<0.3)$ and low $I_{D} / I_{G}$ dispersion $(<0.3)$, suggesting a low $s p^{3}$ hybridized $\mathrm{C}$ content in the $a-\mathrm{C}$ formed within the indented regions. Therefore, Raman spectroscopy confirmed the formation of $s p^{2}$-bonded aromatic $\mathrm{C}$ clusters by static and dynamic indentations due to amorphization of $\mathrm{B}_{4} \mathrm{C}$. Also, dynamic loading results in a greater level of $\mathrm{C}$ cluster formation compared to static loading. This is also supported from the dispersion of $G$ peak to higher frequency in the visible [Fig. 1(a)] and uv Raman spectra [Fig. 1(c)] for dynamic indentation compared to the static indentation. ${ }^{12,13}$

Figure 2 presents the PL spectra of $\mathrm{B}_{4} \mathrm{C}$ obtained from the unindented surface and the indented regions of static and dynamic indentations. For unindented surface, a weak PL band at $2.4 \mathrm{eV}$ was detected and became stronger for static

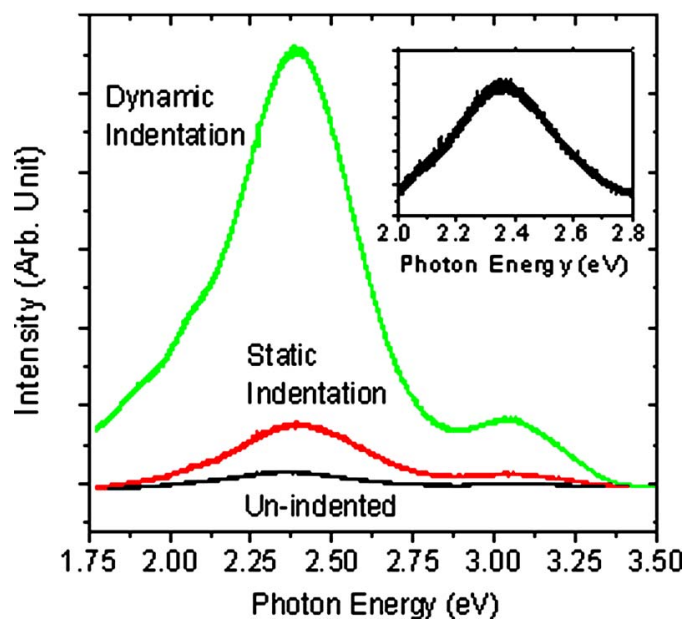

FIG. 2. (Color online) Photoluminescence from the unindented surfaces and damaged regions beneath the static and dynamic indentations.

indentation and strongest for dynamic indentation. A shoulder peak at $\sim 2.05 \mathrm{eV}$ was observed for all the spectra (inset is for unindented regions only). Both type of indented regions exhibited another peak at $\sim 3.05 \mathrm{eV}$ which was again stronger under dynamic indentation compared to static indentation. The PL band at $\sim 2.05 \mathrm{eV}$ is associated with the optical band gap of $\mathrm{B}_{4} \mathrm{C}$. ${ }^{14}$ The other two PL signals (at $\sim 2.4$ and $\sim 3.05 \mathrm{eV}$ ) are not associated with $\mathrm{B}_{4} \mathrm{C}$ as they appear well above the optical band gap and their origin is explained as follows. Amorphous carbon $(a-\mathrm{C})$ and hydrogenated $a-\mathrm{C}$ $(a-\mathrm{C}: \mathrm{H})$ films exhibit a broad PL band from $\sim 1.8$ to $3.7 \mathrm{eV}{ }^{15}$ These films contain $s p^{2}$-bonded $\mathrm{C}$ clusters embedded within $a-\mathrm{C}$ matrix. Their band gaps depend on the size and distribution of the $s p^{2} \mathrm{C}$ clusters. Since Raman spectra indicated $a-\mathrm{C}$ structures within the indented regions, we rationalize that the PL spectra detected here are attributed to radiative recombination mechanism of photoexcited electrons and holes in localized tail states within $s p^{2} \mathrm{C}$ clusters. ${ }^{15}$ Similar to Raman spectra, PL results also indicate the presence of more aromatic $s p^{2} \mathrm{C}$ clusters within dynamically indented regions.

To further clarify the structure of $a-\mathrm{B}_{4} \mathrm{C}$, FTIR spectra were collected from unindented and indented areas (see Fig. 3). All these peaks are similar (except one to be discussed later) and characteristic of crystalline $\mathrm{B}_{4} \mathrm{C}$. The FTIR peak at

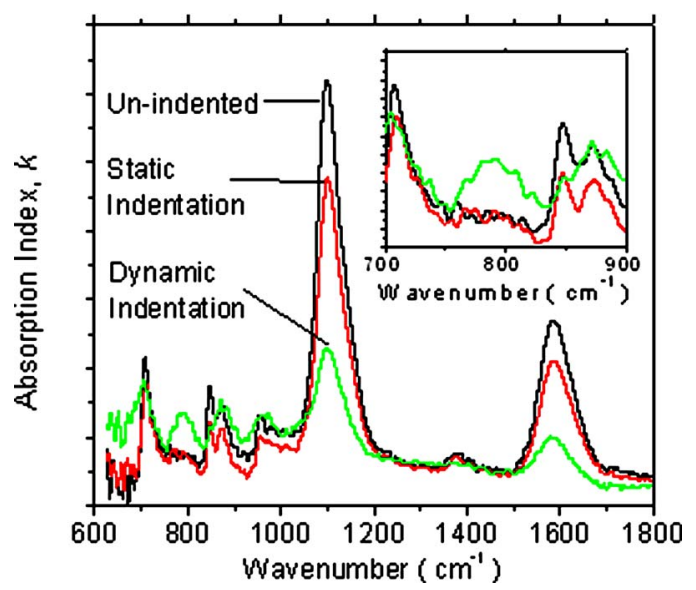

FIG. 3. (Color online) FTIR spectra from the unindented surfaces and damaged regions beneath the static and dynamic indentations. 


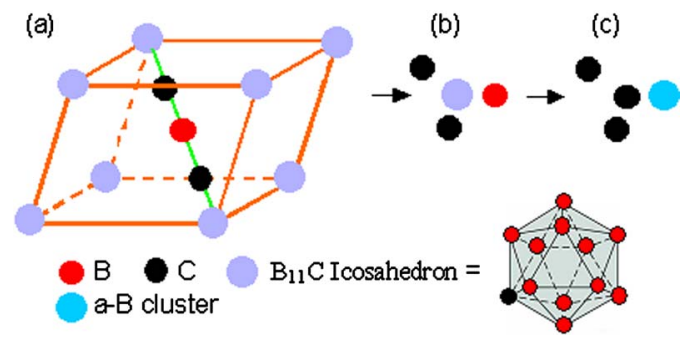

FIG. 4. (Color online) Schematic of (a) a rhombohedral unit cell of $\mathrm{B}_{4} \mathrm{C}$ with eight $\mathrm{B}_{11} \mathrm{C}$ icosahedrons at the corners. (b) Amorphization of each unit cell will form two carbon and one boron atoms and a $\mathrm{B}_{11} \mathrm{C}$ icosahedron. (c) One $\mathrm{B}_{11} \mathrm{C}$ icosahedron and one boron atom will reorganize into one amorphous boron $(a-\mathrm{B})$ cluster and a carbon atom that form carbon clusters with adjacent carbon.

$\sim 1100 \mathrm{~cm}^{-1}$ corresponds to the $\mathrm{B}-\mathrm{C}$ stretching vibration whereas the peak around $1590 \mathrm{~cm}^{-1}$ originates from the stretching of $\mathrm{CBC}$ chains ${ }^{16}$ present along one of the body diagonals of the rhombohedral unit cell of $\mathrm{B}_{4} \mathrm{C}$ (Ref. 6) [see Fig. 4(a)]. The intensities of these peaks gradually decrease in succession from the unindented surface to static to dynamic indentations. This trend clearly indicates structural distortion in $\mathrm{B}_{4} \mathrm{C}$ during indentation. Decreased intensity of FTIR peaks from static to dynamic indentations suggests a greater amorphization or structural disorder. The only difference was the appearance of an infrared (IR) band between $\sim 760$ and $830 \mathrm{~cm}^{-1}$ (shown in the inset) for dynamic indentation. This peak covers the known IR signal for free icosahedral $\mathrm{B}_{12}$ molecules. ${ }^{17,18}$ Due to its broad distribution, it is more appropriate to assign this IR band to amorphous B clusters, in consistent with a reported data. ${ }^{18}$ Therefore, FTIR clearly suggests the formation of $a$-B clusters within the $a-\mathrm{B}_{4} \mathrm{C}$ created by dynamic indentation although no such evidence was observed in the FTIR spectrum for static indentation.

Finally, we present a schematic of the formation of $a-\mathrm{C}$ and $a$-B clusters. $\mathrm{B}_{4} \mathrm{C}$ has a rhombohedral unit cell with eight $\mathrm{B}_{11} \mathrm{C}$ icosahedrons at the corners [see Fig. 4(a)]. Amorphization causes each unit cell to collapse into two $\mathrm{C}$ atoms, one $\mathrm{B}$ atom, and a $\mathrm{B}_{11} \mathrm{C}$ icosahedron [Fig. 4(b)]. The possible mechanism could have been accompanied by the col- lapse of $\mathrm{B}_{11} \mathrm{C}$ icosahedron, which may be energetically more stable to release the $\mathrm{C}$ atom and replace with a $\mathrm{B}$ atom. This reorganizes into one $a$ - $\mathrm{B}_{12}$ cluster and one $\mathrm{C}$ atom to form $\mathrm{C}$ clusters with adjacent $\mathrm{C}$ atoms [Fig. 4(c)].

In summary, we have shown that $a$-C clusters are formed in the indented regions from Raman and PL spectroscopy. FTIR analysis reveals the existence of $a$-B clusters within the dynamically indented region.

This work is funded by the U.S. National Science Foundation (Grant No. CMS-0324461) with Ken Chong as the program manager. One of the authors (Y.K.Y.) acknowledges the support from NSF CAREER award (DMR-0447555 managed by David Nelson).

${ }^{1}$ M. Chen, J. W. McCauley, and K. J. Hemker, Science 299, 1563 (2003).

${ }^{2}$ D. Ghosh, G. Subhash, T. S. Sudarshan, R. Radhakrishnan, and X.-L. Gao, J. Am. Ceram. Soc. 90, 1850 (2007).

${ }^{3}$ D. Ge, V. Domnich, A. Juliano, E. A. Stach, and Y. Gogotsi, Acta Mater. 52, 3921 (2004).

${ }^{4}$ X. Q. Yan, W. J. Li, T. Goto, and M. W. Chen, Appl. Phys. Lett. 88, 131905 (2006).

${ }^{5}$ G. Fanchini, J. W. McCauley, and M. Chhowalla, Phys. Rev. Lett. 97, 035502 (2006).

${ }^{6}$ R. Lazzarari, N. Vast, J. M. Besson, S. Baroni, and A. D. Corso, Phys. Rev. Lett. 83, 3230 (1999).

${ }^{7}$ I. Jimenez, D. G. J. Sutherland, T. v. Buuren, J. A. Carlisle, L. J. Terminello, and F. J. Himpsel, Phys. Rev. B 57, 13167 (1998).

${ }^{8}$ G. Subhash, ASM Handbook®, Mechanical Testing and Evaluation, ASM Handbook vol. 8, (ASM International, Materials Park, Ohio, 2000), p. 519.

${ }^{9}$ Y. K. Yap, S. Kida, T. Aoyama, Y. Mori, and T. Sasaki, Appl. Phys. Lett. 73, 915 (1998).

${ }^{10}$ Y. K. Yap, M. Yoshimura, Y. Mori, and T. Sasaki, Appl. Phys. Lett. 80, 2559 (2002).

${ }^{11}$ M. Ramsteiner and J. Wanger, Appl. Phys. Lett. 51, 1355 (1987).

${ }^{12}$ A. C. Ferrari and J. Robertson, Phys. Rev. B 64, 075414 (2001).

${ }^{13}$ A. C. Ferrari and J. Robertson, Phys. Rev. B 61, 14095 (2000).

${ }^{14}$ H. Werheit, J. Phys.: Condens. Matter 18, 10655 (2006).

${ }^{15}$ J. Xu, J. Mei, X. Huang, W. Li, Z. Li, X. Li, and K. Chen, J. Non-Cryst. Solids 338-340, 481 (2004).

${ }^{16} \mathrm{H}$. Werheit, T. Au, and R. Schmechel, J. Solid State Chem. 154, 79 (1999).

${ }^{17}$ C. L. Beckel, M. Yousaf, M. Z. Fuka, S. Y. Raja, and N. Lu, Phys. Rev. B 44, 2535 (1991).

${ }^{18}$ K. Shirai, S. Emura, S.-i. Gonda, and Y. Kumashiro, J. Appl. Phys. 78, 3392 (1995). 